\title{
Critical Care Nurses' Perceptions towards the Challenges to Adoption of Evidence-Based Practice in the Intensive Care Units (ICUs)
}

\author{
Amina Hemida Salem, Lecturer \\ Critical Care and Emergency Nursing, Faculty of Nursing, Alexandria University
}

\begin{abstract}
Intensive care is a specialty characterized by its complexity, the frequency of life-threatening conditions, and the need for rapid decision-making. Although the adoption of evidence-based practice $(E B P)$ to the critical care nursing practice improves patient outcomes and reduces costs and the risk of harm, there is a gap between recommendations for EBP and critical care nurses' actual practice in intensive care units. Besides, the range of challenges regarding the adoption of evidence-based practice has been identified and extensively determined by researchers in many countries. Objective: Explore the critical care professional nurses' perceptions towards challenges to the adoption of evidence-based practice in intensive care units. Settings: Data were collected from all ICUs in three teaching hospitals at the University of Alexandria. Subjects: A convenient sample of 100 professional nurses working in the ICUs was recruited. Tool: Data were collected using adapted, self-reported, paper-pencil, and two-part questionnaire. Results: The study included 100 nurses working in the ICU. Among all the challenges that hindered the adoption of EBP in ICUs, "Insufficient time to read about or implement new ideas because of the shortage of nurses' number, heavy workload \& a high number of patients" was the highest organizational challenge. The most frequent individual challenge was "The workload is too high to keep up to date with all new evidence". The highest research quality challenge was "Research reports/articles are not readily available". Conclusion: This study reveals that unfamiliarity about concept of EBP and lack of training as well as other organizational, individual and research factors are challenges facing adoption of EBP. The findings of the current study can help identify challenges that effectively influence EBP adoption in the ICUs and overcome them. Recommendations: Intensive care authorities should make EBP a cornerstone for the provided nursing care and create a comprehensive strategy for enhancing EBP skills through appropriate training.
\end{abstract}

$\underline{\text { Keywords: }}$ Critical Care Nurses; Evidence-Based Practice; Challenges; Intensive Care Units.

\section{Introduction}

Critical care nurses are frequently facing life-threatening situations that require rapid decision-making to save the patient's life. Evidence-based practice (EBP) is seen to solve these situations. Additionally, evidence-based practice (EBP) is a wave for the future. It is being identified as an essential key to quality, excellence, and competence in critical care nursing and nursing generally. Incorporation of evidence into nursing practice is necessary to provide scientifically sound patient care ${ }^{(1)}$. Intensive care nurses (ICNs) are essential in the care of critically ill patients to achieve the common goals of nursing care, provide optimal quality of care, promote the patients' safety and prevent further complications. The adoption of Evidence-based nursing practice (EBP) is a tool to accomplish all of these goals. In the intensive care unit, the adoption of evidence - care practice should be considered a norm. To do this, critical care nurses must possess two essential things. The first requires critical care nurses to question traditional care methods and implement current evidence to better meet patient needs. The second step necessitates a better understanding of $\mathrm{EBP}^{(2,3)}$.

There are several definitions of EBP in the literature. All of them, however, have the same keywords. Integrating the best research findings and other forms of evidence to guide practice, nurses' expertise and patients' preferences are just a few of them. 
Furthermore, there were numerous benefits to using EBP to provide critical care services in the ICU. EBP ensures that critical care nurses provide up-to-date patient care, resulting in better patient outcomes. Evidence-based practice also benefits nursing as a profession by promoting selfconfidence in decision-making, which leads to better outcomes ${ }^{(4-8)}$.

Adoption of the evidence to practice is a long process. However, the patients' safety, reducing the health care costs, and recommendations of accreditation and governmental agencies make the adoption of the evidence is a must ${ }^{(9)}$. To solve a clinical problem and assist healthcare professionals in making decisions, EBP is implemented in six major steps. The first step starts with the patient; determine a clinical problem or question from the patient's care. Then, construct a well-built clinical question derived from the case. Nurses must search the literature for clinically relevant articles that explain the problem the patient may be experiencing after formulating the clinical question. Test that evidence for its validity and applicability. Then, return to the patient, integrate the evidence with clinical expertise and patient preferences, apply it to practice, and finally, evaluate the patient's outcome and the nurses' performance ${ }^{(10,11)}$.

Nurses are essential in formulating patient care and safety clinical questions. However, several challenges or barriers have been identified that prevent critical care nurses in ICUs from adopting EBP. According to the findings of the evaluations, both organizational and human factors are related to EBP implementation barriers. Identifying these barriers or challenges could assist hospital administrators in avoiding and resolving these issues. Also, nurses need to develop essential knowledge and skills about research and evidence-based practice to use the best evidence to provide the healthcare required to improve healthcare and cost-saving ${ }^{(12-15)}$.

Significance of the study:
Evidence-based practice should be adopted to improve the quality of the nursing care provided to critically ill patients in intensive care units and reduce costs. This study explores the challenges that interfere with the nurses' efforts to adopt the evidence-based practice in their care. Besides, nursing directors, educators, and hospital directors may use the findings of this study to overcome challenges and help the nurses benefit from evidence by enhancing their understanding of the evidence-based practice. Therefore, patients' safety and positive outcomes might be improved. Additionally, the findings may raise the intensive care authorities' awareness toward enhancing the patients' care and safety.

\section{Aim of the Study}

The study aimed to explore the critical care professional nurses' perceptions of challenges to the adoption of evidence-based practice in intensive care units.

\section{Research Question}

What are the challenges interfering with the adoption of EBP in ICUs?

\section{Materials and Method}

\section{Materials}

Design: A cross-sectional descriptive design was recruited to conduct the current study.

Settings: Data were collected from all ICUs in three teaching hospitals at the University of Alexandria (Main University Hospital, University Students' Hospital, and Somouha University Hospital).

Subjects: A convenient sample of 100 professional nurses working in the ICUs was recruited. Only 73 nurses responded and returned the questionnaires.

\section{Inclusion criteria:}

1. Professional nurses with a bachelor degree and above.

2. Nurses had $\geq$ five years of experience.

3. Nurses with senior positions (head nurse, senior shift). 
Tool: The questionnaire was adapted from other questionnaires used in some previous EBP studies (16 - 20). These questionnaires were studied, reviewed, and some statements were taken from each questionnaire. One of these questionnaires was available only in the Farsi language, and it was translated to English using Farsi - English Language Dictionary before its application. After the questionnaire was fully structured, it was translated into Arabic based on the recommendation experts.

A three - Likert Scale (Agree, Unsure, and Disagree) was used. The new version of the questionnaire comprises two main parts; part I was developed by the researcher to collect demographic and clinical information of participants such as age, sex, level of education, position in ICU, years of experience. Part II aimed to collect the nurses' perceptions regarding the different challenges namely (Organizational (10 Qs.), Individual (11 Qs.) and Research Quality (6 Qs.) that might prevent or interfere with the adoption of EBP.

\section{Method}

- An official letter from the researcher was directed to the Directorate of selected Hospitals to obtain their approval to carry out the study.

- Meetings were held with the directors of the selected settings to clarify the study purpose and gain their cooperation and support during data collection.

- Tool: part I was developed by the researcher to collect the demographic and clinical data of the participants. Part II was adapted from other studies, which aimed to investigate the challenges that interfere with the implementation of EBP in different settings and different countries. One of the recruited questionnaires was in Farsi Language. It was translated into English by the researcher.
- The questionnaire was tested for face and content validity by a panel of experts from academia and clinical settings. Some changes (rephrasing of some statements) were done based on the experts' feedback.

- Cronbach alpha coefficients $(\alpha)$ were used to assess the internal consistency of each category in part II of the questionnaire. The Cronbach alpha for the three categories was $0.71,0.70$, and 70 , indicating that the information gathered using this questionnaire was adequate or acceptable. To test the clarity and applicability of the tool, a pilot study was conducted on $10 \%$ (8 nurses) of the study sample, and nurses who participated in the pilot study were excluded.

- Data were collected using Questionnaires. The questionnaires were distributed to the nurses by handing them over to the head nurses.

\section{Ethical considerations:}

Ethical approval was obtained from the Ethical Committee in the Faculty of Nursing at the University of Alexandria. Permission to conduct the study was obtained from the responsible authorities in the selected Hospitals. Written consent was obtained from the participants after explaining the aim of the study. All participants were informed that their participation is voluntary and they can withdraw from the study at any time without any penalty. Anonymity and confidentiality of the data were assured. Confidentiality of the data was ascertained.

\section{Statistical Analysis}

All statistical tests were two-sided and were performed using IBM SPSS statistics program version 21. Demographic \& clinical variables were summarized by frequency and percent. Nurses' responses on the Likert scale (agree, unsure, and disagree) to individual questions were summed to calculate the total score per each domain for organizational, individual, and research 
quality challenges. The score was converted into a percentage to allow comparison of scores between different themes by the following equation (the total score / maximum possible score $) \times 100$. KruskalWallis test was performed to compare the median total domains' score between different demographic characteristics of included nurses. Significant results were further compared by the Mann-Whitney test with an adjusted $p$-value for pairwise comparisons. The choice of the test was based on variables' distribution by the Kolmogorov-Smirnov test. $\mathrm{P} \leq 0.05$ was the selected level of significance in this study.

\section{Results}

One hundred nurses received the questionnaire, 73 nurses returned it (response rate of $73 \%$ ).

Table (1) illustrates the percent distribution of the critical care nurses according to their demographic and clinical characteristics. Among the entire sample, the majority were married, females, and aged between 36 - more than 46 years $(80.8 \%$, $79.3 \%$, and $94.5 \%$, respectively). Besides, most of the participants $(91.8 \%)$ were employed with a Bachelor's degree, and about two-thirds $(60.5 \%)$ had job experience 15 years and above $(64.4 \%)$. Regarding the nurses' positions in the ICUs, nearly half of the sample was head nurses (49.3\%), followed by charge nurses, staff nurses, and nurses educators were the least percent $(27.4 \%, 13.7 \% \& 9.6 \%$, respectively). Concerning the evidence-based practice, slightly more than half of the sample did not hear about this type of practice (54. 8\%). Most of them did not ever attend a lecture, workshop, or training about evidence-based practice $(83.6 \%)$. Finally, conduction of scientific research or even participation with others was reported by only $27.4 \%$. However, about three-quarters of the sample did not conduct or participate in any research activities $(72.6 \%)$.

Table (2) presents an analysis of the critical care nurses' perceptions of the organizational challenges to the adoption of evidence-based practice. It can be noted that three of the challenges were agreed upon by more than $90 \%$ of the study sample; "Insufficient time to read about or implement new ideas because of a shortage of nurses' number, heavy workload \& the high number of patients" was agreed by most of the sample (94.5\%), "Lack of trained staff or mentor who knows how to adapt the EBP in patients' care" (93.2\%), and "Limitation of the resources required for adoption and implementation of EBP including computers and internet access (90.4\%). Additionally, "Inadequate support to translate research results into practice and lack of motivation (intrinsic and/or extrinsic) for nurses who attended in-service education about EBP" were equally agreed by the participants (89\%). Similarly, equal percent of the agreement was given to "the nurse does not have enough authority to change in patient care procedures, lack of access to a rich library with nursing journals, and lack of access to a rich library with nursing journals (87.7\%)". Moreover, "lack of cooperation and participation of physicians in using evidence in care and "failure to attend conferences, seminars, or workshops on the importance of using evidence in nursing care" was agreed by $(80.8 \%$ \& $75.3 \%$ ) of the participants respectively.

Figure (1) shows a list of the top five organizational challenges to the adoption of evidence-based practice (EBP). "Insufficient time to read about or implement new ideas because of heavy workload \& the high number of patients $(94.5 \%)$, lack of trained staff who knows how to adapt the EBP in patients' care $(93.2 \%)$, insufficient leadership support to translate research results into practice $(90.4 \%)$, limitation in the facilities required for the implementation of EBP such as computers and internet access (89\%), and lack of motivation (financial incentives, certificates, etc.) for nurses who attend in-service education about $\operatorname{EBP}(89 \%)$. 
Table (3) illustrates an analysis of the critical care nurses' perceptions of the individual challenges to the adoption of evidence-based nursing practice. The findings revealed that nearly all of the participants (95.9\%) agreed that "the workload is too high to keep up to date with all new evidence" was the highest individual challenge that hindered the adoption of EBP. Besides, more than three-quarters of the participants voted to "the nurse does not feel capable of evaluating the quality of the research, lack of nurses' sufficient computer skills, lack of nurses' knowledge regarding evidence-based practice, lack of nurses' knowledge regarding the research process, the nurse is unwilling to change/try new ideas, and the nurse is isolated from knowledgeable colleagues within whom to discuss the research" as critical challenges $(80.8 \%, 80.8 \%, 78.1 \%, 76.7 \%, 75.5 \%$, and $75.3 \%$ respectively). However, the least percentage of agreement was given to the rest of the challenges "Reluctance to take care of the patient away from the traditional (routine) method of the patient $(74.0 \%)$, "the nurse feels the benefit of changing practice will be minimal $(72.6 \%)$ ', 'the nurse sees little or no benefit for herself $(69.9 \%)$ ", "the nurse is unwilling to change/try new ideas $(57.5 \%)$ ", and "insufficient proficiency in the English language (50.7\%)".

Figure (2) reveals a list of the top five individual challenges to the adoption of evidence-based practice (EBP). "The workload is too high to keep up to date with all new evidence", "The nurse does not feel capable of evaluating the quality of the research, lack of nurses", "Lack of nurses' knowledge regarding evidence-based practice", "Lack of nurses' sufficient computer skills, and "Lack of nurses' knowledge regarding the research process" were agreed by the highest agreement scores among the nurses' participants $(95,9 \%$, $80,8 \%, \quad 80.8 \%, \quad 78.8 \%$, and $76.7 \%$ respectively) as the most critical individual challenges.
Table (4) shows an analysis of the quality of research challenges to the adoption of evidence-based nursing practice. More than three-quarters of the nurses $(82.2 \%$ \& $78.1 \%)$ agreed that "Research reports/articles are not readily available". About two-thirds of the sample agreed that "Statistical analysis is not understandable", "The criteria required for implementing research results in practice are inadequate", "The nurse is uncertain or confident about whether to believe the results of the research", and "Most research articles are not relevant to the daily patient's practice" $(72.6 \%, 71.2 \%, 69.9 \%$, and $68.5 \%)$.

Table (5) shows the relationship between demographic \& clinical variables and organizational, individual, and research quality-related challenges to the adoption of evidence-based practice. Years of experience had a statistically significant association with challenges to the adoption of evidence-based practice faced by nurses, which were linked to organizational and individual factors. $\left({ }^{\mathrm{KW}} \mathrm{X}\right.$ : Kruskal-Wallis test) $(\mathrm{p}=001 \& \mathrm{p}=009)$. Rather than this, no other significant relationships were found between the other demographic \& clinical variables and organizational, individual, and research quality challenges.

\section{Discussion}

Evidence-based practice has emerged as an innovation for quality improvement and patient safety in intensive care units. Nurses play an essential role in adopting EBP, but they face many challenges. Assessment or exploring these challenges that influencing the adoption of EBP seems necessary. This study aimed to investigate the critical care professional nurses' perceptions of challenges to the adoption of evidence-based practice in intensive care units. Seventythree nurses working in the ICU were recruited. According to the current study's findings, most of the studied sample was females aged between 36 - more than 46 years old, had a Bachelor's degree, employed, and had job experience 15 years 
and above. Also, most of the sample was head nurses and charge nurses (senior shifts). The selection of the nurses who hold bachelor degrees could be explained by the fact that professional nurses' educational preparation differs from that of other nursing categories; diploma nurses. Professional nurses are well equipped with adequate knowledge, skills, and other technological capabilities give them confidence and the ability to assess and identify evidence-based practice. In addition to their positions inside the ICU, the majority, if not all, the professional nurses have occupied the leading positions in the ICUs, such as seniors of the shifts and head nurses that give them the authorities to adopt and/or implement the new ideas. Although all of the participants hold a bachelor's degree and above, and most of them had job experience of 15 years and more. More than half of the participants had never heard of EBP or were unaware of its existence. Most of them had not attended any training(s), or workshop(s) on EBP.

Moreover, most of the participants did not conduct or participate in any research activities. These findings were contrary to other research results that found a strong relationship between levels of education, years of experience, and nurses' knowledge $\mathrm{e}^{(21-24)}$. These findings could be explained by analyzing the challenges mentioned by the nurses who participated in the current study. These challenges were grouped into organizational, individual, and research quality.

\section{Organizational Challenges:}

Among all of ten organizational challenges, The top five challenges, ranked from the highest to the lowest, were: insufficient time to read about or implement new ideas because of the shortage of nurses number, heavy workload \& the high number of patients, lack of trained staff or mentor who knows how to adapt the EBP in patients' care, limitation in the resources and facilities required for the implementation of EBP such as computers and internet access, insufficient leadership support to translate research results into practice, and lack of motivation (financial incentives, certificates of appreciations, etc.) for nurses who attend EBP in-service education.

The most important factor for nurses to adopt EBP appeared to be the availability of sufficient time. One explanation is that EBP is a lengthy process that requires enough time to identify clinical issues that need new ideas to be implemented, transform these issues into well-formulated clinical questions, search the literature for the best available evidence, appraise the retrieved evidence, implement an intervention, then evaluate the implemented intervention effectiveness. In many other studies, insufficient time was cited as the main barrier to implement evidence-based practices, similar to the current research. Azmoude et al. $(2018)^{(25)}$, for example, found that nurses did not have time to read new ideas mentioned by nursing researchers. Furthermore, Khammarnia et al. $(2015)^{(26)}$ found that lack of time to search, retrieve, and read the literature was the most significant barrier to implement EBP for more than two-thirds of the participants.

Jordan et al. (2016) also reached the same conclusion ${ }^{(27)}$. They claimed that nurses did not have enough time to adopt or implement the new EBP ideas. Furthermore, according to Johnston et al. (2016) ${ }^{(28)}$, nurses do not have enough time to stay up to date with new research findings and participate in EBP educational events. Sidani et al. $(2016)^{(29)}$ stated that implementing evidence-based interventions, according to nurses, necessitated free time because it was time-consuming. Also, Kalaldeh et al. $(2014)^{(30)}$ revealed that nurses' empowerment to develop evidencebased guidelines or standards was hampered by a lack of time. Similarly, Renolen and Hjälmhult $(2015)^{(31)}$ discovered that implementing EBP was difficult due to a lack of time. Again, DeBruyn et al. $(2014)^{(32)}$ reported that organizational barriers to implementing EBP in nursing 
practice included insufficient time to read the research, dedicate time to research, and gain education or research skills. Also, a lack of time on the job to implement new ideas is a major perceived barrier to nurses using research ${ }^{(33)}$. Furthermore, Bowers $(2014)^{(34)}$ discovered that more than a third of nurses agreed that they did not have enough time to locate or read research reports.

Lack of trained staff or mentor to adopt and implement the EBP in patients' care was another organizational challenge mentioned by most critical care nurses. The current study revealed that more than fifty percent of the sample did not hear about this type of practice. Most of them did not even attend the lecture, workshop, or training about evidence-based practice. Moreover, the availability of trained staff with adequate EBP training, knowledge, and can lead or mentor the other team in searching; disseminating the EBP culture, and following the implementation process is essential. These roles seem to be dedicated to the quality improvement and nursing education units. Both of these units should work together to prepare the staff, disseminate the EBP culture, initiate, guide, and follow the adoption and implementation of EBP. Lack of trained staff who knows how to adopt and implement the EBP in patients' care was also mentioned by other researchers as an organizational barrier to EBP. Managers did not prioritize learning more about evidence-based practice, according to Renolen \& Hjälmhult $(2015)^{(31)}$.

Furthermore, Bowers (2014) $)^{(34)}$ found that nearly half of the nurses surveyed agreed that in-service EBP education would help them use evidence more effectively. In contrast, only about half of the respondents agreed that an EBP mentor was required for the critical care unit to conduct searches and communicate information to the rest of the team. In-service education, on the other hand, was endorsed by half of the staff as a way to improve understanding and compliance with evidence-based practices. Half of the nurses surveyed agreed that bestpractice guidelines could improve evidencebased practices, while the other half disagreed $^{(35)}$.

Lack of administrative support and motivation was another challenge. Adopting and implementing the new ideas or results of the research or shifting from traditional care to the evidence-based one should be agreed upon and supported by the ICU and hospital administration. Additionally and according to Ford Motivational Systems Theory, there is no doubt that administrative support and motivation are the fuels required for initiating, achieving, and maintaining the organizational goals by the employees ${ }^{(36)}$. Motivation, whatever, extrinsic (tangible rewards such as salary and fringe benefits, security, promotion) or intrinsic (psychological rewards such as receiving appreciation, positive recognition, and being treated in a caring and considerate manner) were insufficient and claimed by the majority of the study sample. Congruent with the result of the current study, lack of motivation \& administrative support was reported by several other studies. According to Johnston et al. (2016) ${ }^{(28)}$, supervision was insufficient, with the main barrier being the organization's lengthy approvals process. Without management's support, nurses believed they had little power to implement new ideas.

Moreover, Renolen and Hjälmhult found the same results $(2015)^{(31)}$. They indicated that it was challenging to put new knowledge into practice when the practice was not required or regulated by anyone. Managers at all levels largely failed to monitor adherence to the use of new knowledge. Nurses also complained about a lack of resources and facilities. Besides, nurses said that the circumstances of their patients and their relationships with coworkers were critical in implementing $\mathrm{EBP}^{(37)}$.

Sidani et al. (2016) ${ }^{(29)}$ stated that a barrier to EBP implementation, according to 
nurses, is the need to collaborate with other health professionals to implement specific evidence-based interventions. EBP's performance could be harmed by a lack of support from the administration and colleagues. More than half of the nurses surveyed cited a lack of authority to change or adapt new evidence as a barrier to EBP implementation (Jordan et al., 2016) ${ }^{(27)}$. Also, roughly a third of the nurses agreed. A quarter of respondents strongly agreed that a barrier to EBP implementation is the lack of authority to change practice in the critical care unit. Similarly, more than half of the nurses said they didn't get enough support from their managers. The nurses were unable to change their patient-care practices due to a lack of support ${ }^{(12)}$.

Most of the study participants identified computers and internet access limitations as significant challenges in adopting and implementing EBP in ICU. Providing the nurses with enough facilities to access the online information, while they are at work and providing the required training on using electronic evidence-based literature could allow them to be familiar with the updates related to patient care. Several other studies mentioned the lack of resources and facilities required for adopting EBP. According to Azmoude et al. (2018) ${ }^{(25)}$, nurses considered inadequate facilities to be an organizational barrier to EBP implementation $^{(37)}$. More than three-quarters of Nepalese nurses cited a lack of resources for implementing research findings as a barrier to research use in clinical practice ${ }^{(38)}$. Khammarnia et al. (2015) came to the same conclusion $^{(26)}$. Similarly, more than twothirds of the nurses cited a lack of adequate computer access as an organizational barrier to EBP implementation ${ }^{(40)}$.

\section{Individual Challenges:}

The findings of the current study highlighted that individual challenges might hamper the adoption of EBP in ICUs. Out of 11 individual challenges, the top five agreed by most of the participants as important factors inferred with their ability to adopt and implement EBP will be discussed in detail. "Workload is too high to keep up to date with all new evidence", this challenge was agreed upon by most nurses. This challenge could be explained by the nurses' inability to complete the multistep EBP process due to a lack of time and physical energy. Most nurses also reported insufficient time as an organizational challenge.

Regarding the other four individual challenges, they include "nurse does not feel capable of evaluating the quality of the research, lack of nurses' knowledge regarding evidence-based practice, lack of nurses' sufficient computer skills, and lack of nurses' knowledge regarding the research process. The lack of knowledge and computer skills among nurses could be explained by time constraints, nurse shortage as the number of patients grows, and a heavy workload. Additionally, heavy workload interferes with the nurses' chance to attend lectures, workshops, or training as it was mentioned by the nurses "Failure to attend conferences, seminars, or workshops on the importance of using evidence in nursing care." that was mentioned by about three - quarters of participants. Nurses must have good computer and searching skills to collect current, relevant, and accurate information quickly, as nursing literature is rapidly growing. Inadequate computer and search skills can lead to the omission of critical information, compromising the quality and safety of patients in ICUs. According to hospital management, nurses' work schedules must be adjusted to allow them to learn and implement EBP. Many other researchers identified little nurses' knowledge regarding the EBP and research process as well as limitation in the computer skills as barriers for EBP.

To investigate EBP implementation barriers among nurses in Iran, Khammarnia et al. $(2015)^{(26)}$ performed a quantitative analytical cross-sectional study. The findings revealed that more than half of the nurses who took part agreed that a common 
barrier to EBP implementation is a lack of knowledge ${ }^{(41)}$. Also, to evaluate the individual and organizational barriers to EBP implementation among nurses in a private intensive care unit (ICU), Jordan et al. $(2016)^{(27)}$ carried out a quantitative exploratory study. The results revealed that nurses' familiarity with EBP is lacking, with less than half of the participants incorrectly defining and understanding the concept ${ }^{(40)}$.

\section{Quality of Research Challenges:}

Other challenges to the adoption of EBP identified in this study were related to the quality of research. Six research quality challenges were identified and ranked from the highest to the lowest. These challenges include: research reports/articles are not readily available, implications for practice are not made clear, statistical analysis is not understandable, the criteria required for implementing research results in practice are inadequate, the nurse is uncertain or confident about whether to believe the results of the research and most research articles are not relevant to my daily routine. Nurses who haven't been exposed to statistical and research terminologies and concepts may face serious difficulties. These issues are likely to be mitigated to some extent by a well-designed training program.

\section{Conclusion}

Based on the results of the current study, it can be concluded that:

1. Lack of nurses' familiarity with EBP was found to be a barrier to EBP implementation.

2. Among all of these challenges:

- $\quad$ Insufficient time to read about or implement new ideas because of the shortage of nurses' number, heavy workload $\&$ high number of patients" was the top of the organizational challenges,

- $\quad$ "The workload is too high to keep up to date with all new evidence" was the top of the individual challenges, and

- "Research reports/articles are not readily available" was the top of research quality challenges.

\section{Recommendations}

- Create a comprehensive strategy for enhancing EBP skills through appropriate training. Furthermore, nursing education units should take an active role in helping nurses develop adequate information literacy skills.

- Encourage and facilitate nurses' participation in ongoing training and in-service education to improve their knowledge and skills in applying evidence-based practice.

- Set aside time for the nurse to conduct or search for updates in the patients' practice, ensure that nurses have the resources they require, and adequate supervision and mentorship to help them adopt and implement evidence-based practice and improve the quality of their care.

- Update the nursing schools curricula and incorporate a course about EBP and enhance the students' research utilization and statistical skills. Evidence-based practices help intensive care nurses (ICNs) to provide patient care based on research rather than traditions, myths, or advice of colleagues. 
Table (1): Percent Distribution of the Studied Professional Critical Care Nurses According to Their Demographic and Clinical Characteristics

\begin{tabular}{|c|c|}
\hline Characteristics & $\begin{array}{c}\text { Frequency }(\%) \\
(n=73)\end{array}$ \\
\hline $\begin{array}{l}\text { 1. } \\
\text { Age (Years): } \\
-\quad 25-35 \\
-\quad 36-45 \\
-\quad \geq 46\end{array}$ & $\begin{array}{c}4(5.5) \\
36(49.3) \\
33(45.2)\end{array}$ \\
\hline $\begin{array}{ll}\text { 2. } & \text { Sex: } \\
- & \text { Female } \\
- & \text { Male } \\
\end{array}$ & $\begin{array}{c}71(97.3) \\
2(2.7) \\
\end{array}$ \\
\hline $\begin{array}{ll}\text { 3. } & \text { Marital Status: } \\
- & \text { Single } \\
- & \text { Marries }\end{array}$ & $\begin{array}{l}14(19.2) \\
59(80.8)\end{array}$ \\
\hline $\begin{array}{ll}\text { 4. } & \text { Level of Education: } \\
- & \text { Bachelor } \\
- & \text { Master } \\
- & \text { Doctorate }\end{array}$ & $\begin{aligned} 67 & (91.8) \\
4 & (5.5) \\
2 & (2.8)\end{aligned}$ \\
\hline $\begin{array}{ll}\text { 5. } & \text { Professional Year(s) of Experience In ICU: } \\
- & 5 \text { Years to }<10 \text { Years } \\
- & 10 \text { Years to }<15 \text { Years } \\
- & 15 \text { Years \& more }\end{array}$ & $\begin{array}{c}18(24.6) \\
8(11) \\
47(64.4)\end{array}$ \\
\hline $\begin{array}{ll}\text { 6. } & \text { The Current Position in ICU: } \\
- & \text { Staff Nurse } \\
- & \text { Charge Nurse } \\
- & \text { Head Nurse } \\
- & \text { Nurse Educator } \\
\end{array}$ & $\begin{array}{c}10(13.7) \\
20(27.4) \\
36(49.3) \\
7(9.6)\end{array}$ \\
\hline $\begin{array}{ll}\text { 7. } & \text { Did you hear about evidence-based practice (EBP)? } \\
- & \text { Yes } \\
- & \text { No }\end{array}$ & $\begin{array}{l}33(45.2) \\
40(54.8)\end{array}$ \\
\hline $\begin{array}{l}\text { 8. Have you ever received lecture(s), workshop(s), or training about } \\
\text { EBP? } \\
-\quad \text { Yes } \\
-\quad \text { No } \\
\end{array}$ & $\begin{array}{l}12(16.4) \\
61(83.6) \\
\end{array}$ \\
\hline $\begin{array}{l}\text { 9. Have you ever participated in any research activities, alone or in a } \\
\text { team? } \\
-\quad \text { Yes } \\
-\quad \text { No }\end{array}$ & $\begin{array}{l}20(27.4) \\
53(72.6)\end{array}$ \\
\hline
\end{tabular}


Table (2): Organizational Challenges to the Adoption of Evidence-Based Practice as Perceived by the Studied Professional Critical Care Nurses

\begin{tabular}{|c|c|c|c|}
\hline Challenges & $\begin{array}{c}\text { Agree } \\
(\%)\end{array}$ & $\begin{array}{c}\text { Unsure } \\
(\%)\end{array}$ & $\begin{array}{l}\text { Disagree } \\
(\%)\end{array}$ \\
\hline $\begin{array}{l}\text { 1. The nurse does not have enough authority to change patient care } \\
\text { procedures. }\end{array}$ & 87.7 & 2.7 & 9.6 \\
\hline $\begin{array}{l}\text { 2. Insufficient time to read about or implement new ideas because of the } \\
\text { shortage of nurses' number, heavy workload \& the high number of } \\
\text { patients. }\end{array}$ & 94.5 & 1.4 & 4.1 \\
\hline $\begin{array}{l}\text { 3. Limitation in the resources and facilities required for implementing } \\
\text { EBP, such as computers and internet access. }\end{array}$ & 90.4 & 2.7 & 6.8 \\
\hline $\begin{array}{l}\text { 4. There is a gap between the academia (site of research production) } \\
\text { and clinical settings }\end{array}$ & 87.7 & 2.7 & 9.6 \\
\hline $\begin{array}{l}\text { 5. Lack of trained staff or mentor who knows how to adapt the EBP in } \\
\text { patients' care. }\end{array}$ & 93.2 & 2.7 & 4.1 \\
\hline $\begin{array}{l}\text { 6. Failure to attend conferences, seminars, or workshops on the } \\
\text { importance of using evidence in nursing care. }\end{array}$ & 75.3 & 13.7 & 4.1 \\
\hline $\begin{array}{l}\text { 7. Insufficient leadership support to translate research results into } \\
\text { practice. }\end{array}$ & 89 & 2.7 & 9.6 \\
\hline $\begin{array}{l}\text { 8. Lack of cooperation and participation of physicians in using evidence } \\
\text { in care. }\end{array}$ & 80.8 & 11 & 8.2 \\
\hline 9. Lack of access to a rich library with nursing journals. & 87.7 & 2.7 & 9.6 \\
\hline $\begin{array}{l}\text { 10. Lack of motivation (financial incentives, certificates of appreciation, } \\
\text { etc.) for nurses who attend in-service education about EBP. }\end{array}$ & 89 & 6.8 & 4.1 \\
\hline
\end{tabular}

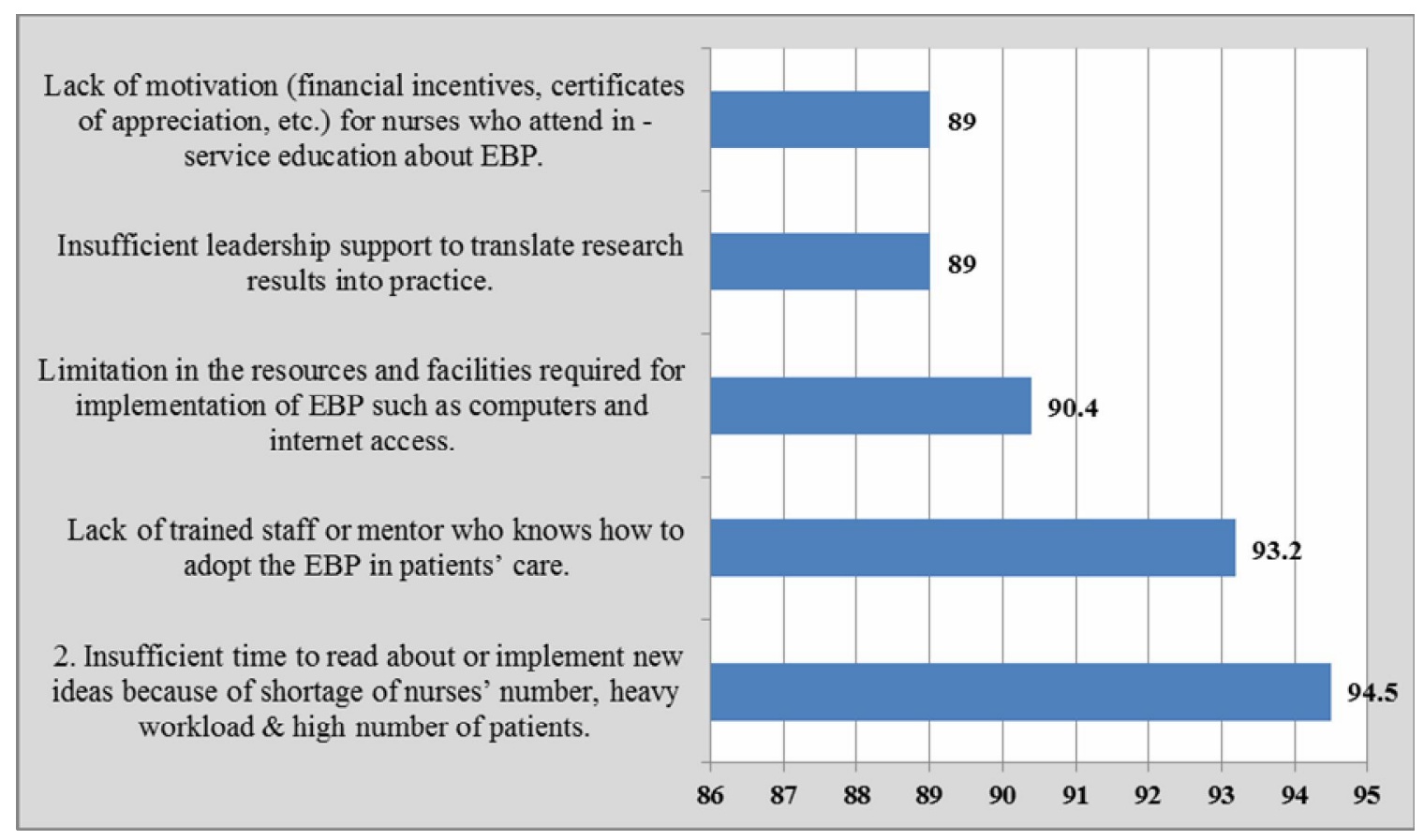

Figure (1): List of the Top Five Organizational Challenges to Adoption of Evidence-Based Practice as Perceived by the Studied Professional Critical Care Nurses 
Table (3): Individual Challenges to Adoption of Evidence-Based Practice as Perceived by the Studied Professional Critical Care Nurses

\begin{tabular}{|l|c|c|c|}
\hline Challenges & $\begin{array}{c}\text { Agree } \\
\mathbf{( \% )}\end{array}$ & $\begin{array}{c}\text { Unsure } \\
\mathbf{( \% )}\end{array}$ & $\begin{array}{c}\text { Disagree } \\
\mathbf{( \% )}\end{array}$ \\
\hline $\begin{array}{l}\text { 1. } \\
\text { The nurses' workload is too high to keep up to date with all } \\
\text { newidence. }\end{array}$ & 95.9 & 1.4 & 2.7 \\
\hline $\begin{array}{l}\text { 2. The nurse does not feel capable of evaluating the quality of } \\
\text { the research. }\end{array}$ & 80.8 & 11 & 8.2 \\
\hline 3. The nurse sees little or no benefit for herself. & 69.9 & 15.1 & 15.1 \\
\hline 4. The nurse is unwilling to change/try new ideas. & 57.5 & 13.7 & 28.8 \\
\hline 5. $\quad \begin{array}{l}\text { The nurse feels the benefit of changing practice will be } \\
\text { minimal. }\end{array}$ & 72.6 & 17.8 & 9.6 \\
\hline $\begin{array}{l}\text { 6. The reluctance of the nurses to take care of the patient away } \\
\text { from the traditional (routine) method of the patient. }\end{array}$ & 74.0 & 16.4 & 9.6 \\
\hline $\begin{array}{l}\text { 7. } \text { The nurse is isolated from knowledgeable colleagues in } \\
\text { academia with whom to discuss the research. }\end{array}$ & 75.3 & 9.6 & 15.1 \\
\hline 8. Lack of nurses' knowledge regarding evidence-based practice. & 80.8 & 9.6 & 9.6 \\
\hline 9. Lack of nurses' knowledge regarding the research process. & 76.7 & 13.7 & 9.6 \\
\hline 10. Lack of nurses' proficiency in the English language. & 50.7 & 32.9 & 16.4 \\
\hline 11. Lack of nurses' sufficient computer skills. & 78.1 & 9.6 & 12.3 \\
\hline
\end{tabular}

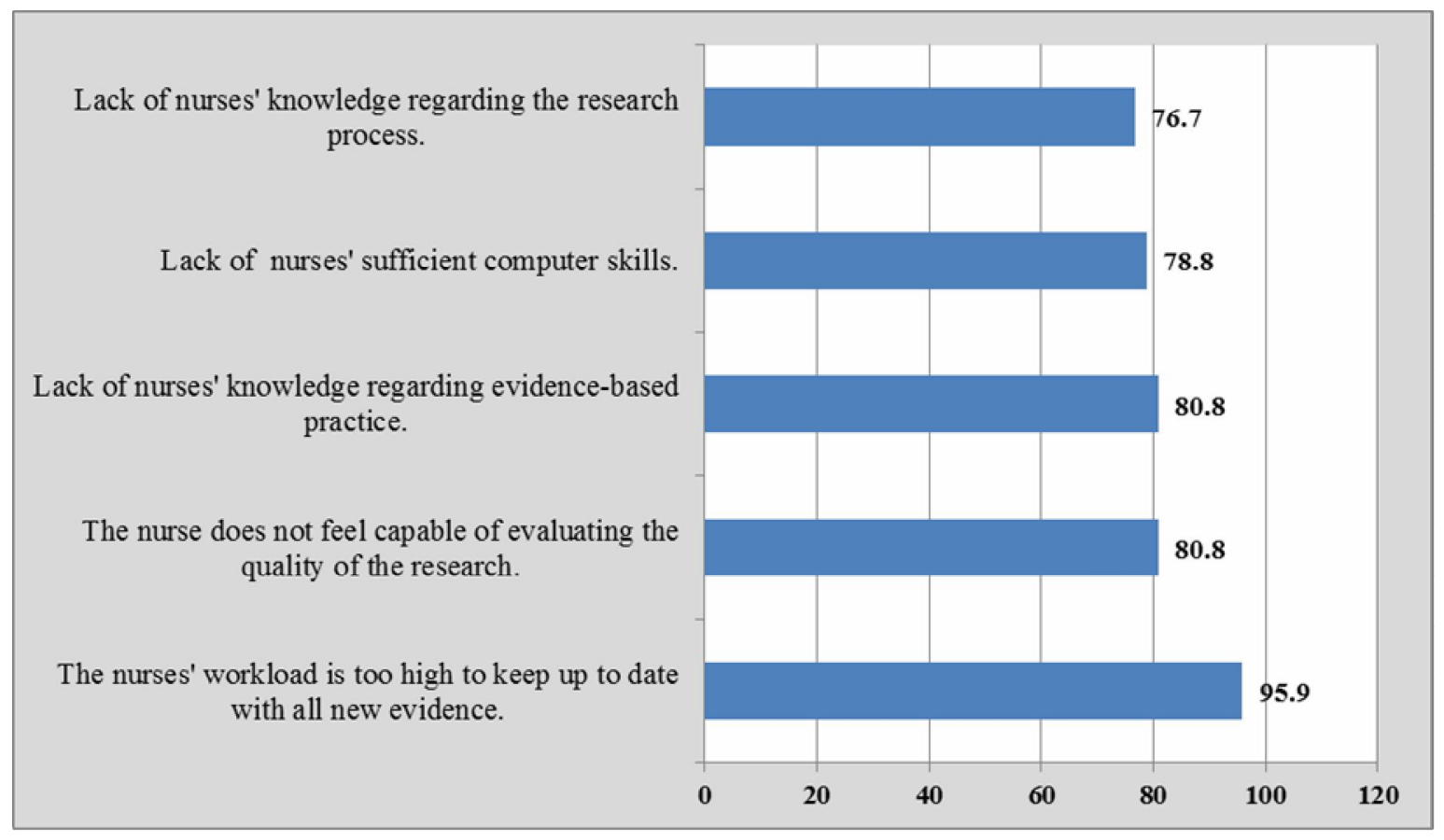

Figure (2): List of the Top Five Individual Challenges to Adoption of Evidence-Based Practice as Perceived by the Studied Professional Critical Care Nurses 
Table (4): Research Quality Challenges to Adoption of Evidence-Based Practice as Perceived by the Studied Professional Critical Care Nurses

\begin{tabular}{|c|c|c|c|}
\hline Challenges & $\begin{array}{c}\text { Agree } \\
(\%)\end{array}$ & $\begin{array}{c}\text { Unsure } \\
(\%)\end{array}$ & $\begin{array}{l}\text { Disagree } \\
(\%)\end{array}$ \\
\hline 1. Statistical analysis is not understandable. & 72.6 & 13.7 & 13.7 \\
\hline 2. Implications for practice are not made clear. & 78.1 & 16.4 & 5.5 \\
\hline 3. Research reports/articles are not readily available. & 82.2 & 15.1 & 2.7 \\
\hline $\begin{array}{l}\text { 4. The nurse is uncertain or confident about whether to believe the } \\
\text { results of the research. }\end{array}$ & 69.9 & 21.9 & 8.2 \\
\hline $\begin{array}{l}\text { 5. The criteria required for implementing research results in practice } \\
\text { are inadequate. }\end{array}$ & 71.2 & 26.0 & 2.7 \\
\hline 6. Most research articles are not relevant to my daily practice. & 68.5 & 28.8 & 2.7 \\
\hline
\end{tabular}

Table (5): Relationship between the Professional Critical care Nurses' Characteristics and Each of the Organizational, Individual, and Quality of Research Challenges

\begin{tabular}{|c|c|c|c|}
\hline $\begin{array}{l}\text { Challenges Md Total } \\
\text { Score/characteristics }\end{array}$ & 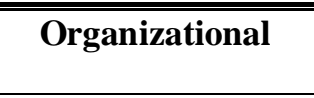 & Individual & "Quality of Research \\
\hline \multicolumn{4}{|l|}{ Age (Years): } \\
\hline $25-35$ & 33.5 & 27 & 16.5 \\
\hline $36-45$ & 33.5 & 31 & 17 \\
\hline$\geq 46$ & 33.0 & 28 & 16.0 \\
\hline${ }^{\mathrm{KW}} \mathrm{X}$ (p-value) & $0.112(0.9)$ & $3.87(0.1)$ & $1.71(0.4)$ \\
\hline \multicolumn{4}{|l|}{ Sex: } \\
\hline Female & 33. $(20-36)$ & $29(19-33)$ & $17(10-18)$ \\
\hline Male & $35(34-36)$ & $30.5(28-33)$ & $16(14-18)$ \\
\hline p-value & $\mathrm{U}=106$, p.231 & $\mathrm{U}=95, \mathrm{p} .457$ & $\mathrm{U}=71, \mathrm{p} 1$ \\
\hline \multicolumn{4}{|l|}{ Marital Status: } \\
\hline Single & $33.5(20-36)$ & $28.5(22-33)$ & $16.5(12-18)$ \\
\hline Married & $33(24-36)$ & $30(19-33)$ & $17(10-18)$ \\
\hline p-value & $\mathrm{U}=470, \mathrm{p} .418$ & $\mathrm{U}=467$, p.447 & $\mathrm{U}=.112, \mathrm{p} .966$ \\
\hline \multicolumn{4}{|l|}{ Level of Education: } \\
\hline Bachelor & $33(24-36)$ & $29(19-33)$ & $16(10-18)$ \\
\hline Master & $32.5(20-36)$ & $30.5(29-33)$ & $17(13-18)$ \\
\hline Doctorate & $34.5(33-36)$ & $29.5(27-32)$ & $16.5(15-18)$ \\
\hline p-value & ${ }^{\mathrm{KW}} \mathrm{X}=.864, \mathrm{p} .649$ & ${ }^{\mathrm{KW}} \mathrm{X}=1.32$, p.515 & ${ }^{\mathrm{KW}} \mathrm{X}=.108, \mathrm{p} .948$ \\
\hline \multicolumn{4}{|c|}{ Professional Year(s) of Experience In ICU: } \\
\hline 6 months to $<5$ Years & $32(20-36)$ & $29(24-33)$ & $17(14-18)$ \\
\hline 5 Years to $<10$ Years & $36(28-36)$ & $31(26-33)$ & 17(14-18) \\
\hline 10 Years to $<15$ Years & $36(33-36)$ & $32.5(29-33)$ & $18(15-18)$ \\
\hline 15 Years \& more & $33(24-36)$ & $28(19-33)$ & $16(10-18)$ \\
\hline p-value & ${ }^{\mathrm{KW}} \mathrm{X}=15.53, \mathrm{p} .001 *^{\ddagger}$ & ${ }^{\mathrm{KW}} \mathrm{X}=11.51, \mathrm{p} .009^{* \#}$ & ${ }^{\mathrm{KW}} \mathrm{X}=3.57, \mathrm{p} .312$ \\
\hline \multicolumn{4}{|c|}{ The current position in ICU: } \\
\hline Staff Nurse & $32.5(24-36)$ & $29.5(24-33)$ & $16.5(14-18)$ \\
\hline Charge Nurse & $34(30-36)$ & $29.5(21-33)$ & $16.5(12-18)$ \\
\hline Head Nurse & $33(26-36)$ & $29(19-33)$ & $16.5(10-18)$ \\
\hline Nurse Educator & $33(20-35)$ & $29(25-32)$ & $17(14-18)$ \\
\hline p-value & ${ }^{\mathrm{KW}} \mathrm{X}=2.53, \mathrm{p} .468$ & ${ }^{\mathrm{KW}} \mathrm{X}=.805, \mathrm{p} .848$ & ${ }^{\mathrm{KW}} \mathrm{X}=.421, \mathrm{p} .936$ \\
\hline
\end{tabular}




\section{References}

1. Lisa A Cranle, Greta G Cummings, Joanne Profetto-McGrath, Ferenc Toth, and Carole A Estabrooks. Facilitation roles and characteristics associated with research use by healthcare professionals: a scoping review. BMJ Open. 2017; Aug 11; 7(8).

2. Abuejheisheh A. et al. Predictors of Intensive Care Unit Nurses' Practice of Evidence-Based Practice Guidelines. INQUIRY: The Journal of Health Care Organization, Provision, and Financing. 2019; 57: 1-7.

3. Morton PG, Fontaine DK. Essentials of Critical Care Nursing: A Holistic Approach. Philadelphia, PA: Wolters Kluwer Health; 2013.

4. Gifford W, Zhang Q, Chen S, Davies B, Xie R, et al. When east meets west: A qualitative study of barriers and facilitators to evidence-based practice in Hunan China. BMC Nursing. 2018; 17: 26-11.

5. A. Sharma et al., "Using digital health technology to better generate evidence and deliver evidence-based care," Journal of the American College of Cardiology. 2018; vol. 71, no. 23: pp. 2680-2690.

6. Naji Alqahtani, Kyeung M. Panagiota Kitsantas, and Margaret Rodan. Nurses' evidence-based practice knowledge, attitudes, and implementation: A cross-sectional study. J Clin Nurs. 2019; Jan;29 (1-2):274-283..

7. Melnyk, B. M., \& Fineout-Overholt, E. Evidence-based practice in nursing and healthcare: A guide to best practice ( $3 \mathrm{rd}$ ed). Philadelphia, PA: Wolters Kluwer Health (2015).

8. John, S. M. Assessing knowledge of evidencebased practice among nurses (Doctoral dissertation). Walden University, (2016).

9. Pryse, Y. M. Using evidence-based practice: The relationship between work environment, nursing leadership, and nurses at the bedside (Doctoral dissertation). Indiana University, (2012).

10. Munirah Alatawi, Eman Aljuhani, Fatimah Alsuiany, and Sara Aljanabi. Barriers of Implementing Evidence-Based Practice in Nursing Profession: A Literature Review. Banakar et al., J Nurs Care, 2019; Volume 9, Issue 1, Pages: 35-42.

11. Marik PE. Evidence-Based Critical Care. New York, NY: Springer; 2015.

12. S. Kc, P. R. Subramaniam, and S. Paudel, "Barriers and Facilitators of Utilizing Research among Nurses in Nepal," Journal of continuing education in nursing.2016; vol. 47, no. 4: pp. 171-179.

13. W. Gifford et al., "When east meets west: a qualitative study of barriers and facilitators to evidence-based practice in Hunan China," BMC nursing. 2018; vol. 17, no. 1: pp. 26-11.

14. P. Jordan, C. Bowers, and D. Morton, "Barriers to implementing evidence-based practice in a private intensive care unit in the Eastern Cape," Southern African Journal of Critical Care. 2016; vol. 32, no. 2: pp. 50-54.

15. D. Dang and S. L. Dearholt, Johns Hopkins nursing evidence-based practice: Model and guidelines. Sigma Theta Tau, 2017.

16. Upton, D., \& Upton, P. Development of an evidence-based practice questionnaire for nurses. Journal of Advanced Nursing. 2006; 53(4): 454-458.

17. Upton, D., Upton, P., \& Scurlock-Evans, L. The reach, transferability, and impact of the evidence-based practice questionnaire: A methodological and narrative literature review. Worldviews on Evidence-Based Nursing. 2014; 11(1): 46-54.

18. Sima Kermanshahi and, Ali Mohammad Parvinian. Barriers to Implementation of Evidence-Based Care: Viewpoints of Nursing Staff. Iranian Journal of Medical Education 2012: 12(2): $83-92$.

19. Funk SG, Champagne MT, Wiese RA, Tornquist EM. BARRIERS: the barriers to research utilization scale. Applied Nursing Research. 1991; 4(1):39-45.

20. Hittle K. et al. Factors Associated With Nurses' Knowledge of and Perceived Value in Evidence-Based Practices. AJCC American Journal of Critical Care. 2020; Volume 29, No. 1.

21. Phillips C. Relationships between duration of practice, educational level, and perception of barriers to implementing evidence-based practice among critical care nurses. Int J Evid Based Healthc. 2015;13(4):224-232.

22. Dana Beth Weinberg, Dianne Cooney-Miner, Jennifer N. and Perloff, P. Analyzing the Relationship between Nursing Education and Patient Outcomes. Journal of Nursing Education. 2012; Volume 3, Issue 2: P4-10.

23. American Association of Colleges of Nursing. Enrollment and graduations in baccalaureate and graduate programs in nursing. Washington, 2019.

24. Blegen, Mary A. et al. Baccalaureate Education in Nursing and Patient Outcomes. JONA: 
Journal of Nursing Administration February 2013, Volume: 43 Number 2, page 89 - 94.

25. Azmoude E, Aradmehr M, Dehghani F. Midwives' attitude and barriers of evidencebased practice in maternity care. Malays $\mathrm{J}$ Med Sci. 2018; 25: 120-128.

26. Khammarnia M, Haj Mohammadi M, Amani Z, Rezaeian S, Setoodehzadeh F. Barriers to implementation of evidence-based practice in Zahedan teaching hospitals, Iran. Nursing Research and Practice. 2015: 357140-357145.

27. Jordan P, Bowers C, Morton D. Barriers to implementing evidence-based practice in a private intensive care unit in the Eastern Cape. Southern African Journal of Critical Care. 2016; 32: 50-54.

28. Johnston B, Coole C, Narayanasamy M, Feakes R, Whitworth G, et al. Exploring the barriers to and facilitators of implementing research into practice. Br J Community Nurs. 2016; 21: 392398.

29. Sidani S, Manojlovich M, Doran D, Fox M, Covell CL, et al. Nurses' perceptions of interventions for the management of patientoriented outcomes: A key factor for evidencebased practice. Worldviews Evid Based Nurs. 2016; 13: 66-74.

30. Kalaldeh MA, Watson R, Hayter M. Jordanian intensive care nurses' perspectives on evidencebased practice in nutritional care. Br J Nurs. 2014; 23: 1023-1029.

31. Renolen Å, Hjälmhult E. Nurse's experience of using scientific knowledge in clinical practice: A grounded theory study. Scand J Caring Sci. 2015; 29: 633-641.

32. DeBruyn RR, Ochoa-Marín SC, Semenic S. Barriers and facilitators to evidence-based nursing in Colombia: Perspectives of nurse educators, nurse researchers and graduate students/Barreras y facilitators en la práctica dela Enfermería Basada en la Evidencia en Medellín, Colombia. Invest Educ Enferm. 2014; 32: 9-21.

33. Farokhzadian J, Khajouei R, Ahmadian L. Evaluating factors associated with implementing evidence-based practice in nursing. J Eval Clin Pract. 2015; 21: 11071113.

34. Bowers CA. Barriers to implementation of evidence-based practices in a critical care unit. Nelson Mandela Metropolitan University, University in Port Elizabeth, South Africa. 2014.

35. Kc S, Subramaniam PR, Paudel S. Barriers and facilitators of utilizing research among nurses in Nepal. J Contin Educ Nurs. 2016; 47: 171179.
36. Ong Choon Hee, and Noor Hayati Binti Kamaludin. Motivation and Job Performance among Nurses in the Private Hospitals in Malaysia. International Journal of Caring Sciences January - April 2016 Volume 9 | Issue 1) Page 342 - 347.

37. A. M. Hutchinson and L. Johnston, "Beyond the BARRIERS Scale: commonly reported barriers to research use," The Journal of Nursing Administration. 2006 vol. 36, no. 4, pp. 189-199.

38. N. M. Solomons and J. A. Spross, "Evidencebased practice barriers and facilitators from a continuous quality improvement perspective: an integrative review," Journal of Nursing Management. 2011; vol. 19, no. 1, pp. 109120.

39. H. Sadeghi-Bazargani, J. S. Tabrizi, and S. Azami-Aghdash, "Barriers to evidence-based medicine: a systematic review," Journal of Evaluation in Clinical Practice. 2014; vol. 20, no. 6 , pp. $793-802$.

40. H. S. Thorsteinsson, "Icelandic nurses' beliefs, skills, and resources associated with evidencebased practice and related factors: a national survey, "Worldviews on Evidence-Based Nursing. 2013; vol. 10, no. 2, pp. 116-126.

41. M. Adib-Hajbaghery, "Evidence-based practice: Iranian nurses' perceptions, "Worldviews on Evidence-Based Nursing. 2009; vol. 6, no. 2, pp. 93-101. 